\title{
Cognitive organization of cognitive activities of students on the basis of effective harmonization of logical and emotional aspects of acquiring of scientific knowledge
}

\author{
A.R. Kamaleeva, L.Yu. Mukhametzyanova, V.M. Nigmetzyanova, N.A. Nozdrina, and E.B. \\ Pokaninova
}

\begin{abstract}
The relevance of the article is due to the fact that cognitive pedagogy has set the task of identifying the patterns of functioning and the formation of learning mechanisms for students in order to increase the effectiveness and quality of higher education in the era of digitalization. The purpose of the article is to reveal the integrative integrity of cognitive-logical and emotional-figurative mechanisms of cognition based on the relationship between the perceptions of the procedural deployment of educational material with the patterns in the presentation of a simultaneous image in the process of semantic disclosure of educational information. The cognitive paradigm is positioned as a methodological basis for the study, based on the appeal to methods, types and technologies of information processing by a person in order to create his own system of knowledge of the world with access to the generation of knowledge. The authors emphasize the importance of using the mechanisms of art in the process of emotionally figurative interpretation of scientific knowledge associated with the hermeneutic direction, according to which it is necessary to prepare students for perception, adjust them to experience and empathy, which contribute to the assimilation of scientific knowledge not reproductively, but constructively, creatively. In the process of experimental work, diagnostics of the dominant perceptual modality and imagination were used in order to identify their role in the organization of educational and cognitive activity in conditions of intensive generation of knowledge.
\end{abstract}

\section{Introduction}

The term "information" from the Latin word "informatio" means information, clarification, presentation. It should be noted that information is not a characteristic of a message, but of a relationship between a message and its consumer. Without the presence of a consumer, at least a potential one, it makes no sense to talk about information. If we talk about the educational process in higher education, the consumers are students, it is for them that the corresponding educational information is prepared.

Modern requirements for the quality of higher education orients teachers towards rethinking the design of the content of disciplines, the educational information that must not only be brought to each student, but also taught to use it when solving production problems in future professional activities. This is complicated by the need to resolve the contradiction 
between the reduction of learning time for the study of disciplines and the need to master the ever-increasing educational information.

A teacher of a higher school must remember that the process of students' cognitive activity organized by him is not identical to the process of scientific cognition, and, most often, the design of the content of an academic discipline does not correspond to the construction of the content of science itself. In addition, the content of the studied disciplines should be adapted to the age, and, most importantly, the cognitive capabilities of the students. This is especially relevant in connection with the fact that we proceed from the fact that "cognitive didactics explores and implements in practice the regularities of functioning and formation of learning mechanisms of students in order to increase the effectiveness and quality of higher education; it uses the principles and concepts of educational psychology, traditional and digital didactics, but transforms and supplements them, adapting them to modern realities" [1].

Modern scientists in the field of cognitive didactics offer original ways of designing the content of academic disciplines (see Table 1).

Table 1. Methods for designing the content of academic disciplines.

\begin{tabular}{|c|c|c|}
\hline № & Main idea & Author \\
\hline 1. & $\begin{array}{c}\text { In the process of "quantization" of a text, three basic techniques } \\
\text { should be included: "reduction (or compression) of the verbal and } \\
\text { symbolic composition of texts; division of texts into parts; the use of } \\
\text { effective }\end{array}$ & $\begin{array}{c}\text { V.S. } \\
\text { Avanesov } \\
\text { (2014) }\end{array}$ \\
\hline 2. & $\begin{array}{c}\text { Development and implementation of didactic multidimensional } \\
\text { technology in the form of design and application of logical-semantic } \\
\text { models, which assumes using both visual and audio forms } \\
\text { for the presentation of new material in order to effectively use } \\
\text { the reserves of both the first and second signal systems in the process } \\
\text { of perception, processing, and comprehension by students } \\
\text { of the educational material [3] }\end{array}$ & $\begin{array}{c}\text { Steinberg } \\
\text { (2013) }\end{array}$ \\
\hline 3. & $\begin{array}{c}\text { The use of potential of the "frame" as a means of forming generalized } \\
\text { cognitive skills [4] }\end{array}$ & $\begin{array}{c}\text { R.V. Gurinf } \\
\text { (2013) }\end{array}$ \\
\hline 4. & $\begin{array}{c}\text { The idea of thickening educational information in higher education } \\
\text { from the perspective of considering two aspects: to know and be able } \\
\text { to when "it is expedient and natural to assimilate knowledge } \\
\text { in a concentrated manner in time, and the ability to master regularly } \\
\text { and distributed in time" [5] }\end{array}$ & $\begin{array}{c}\text { S.P. } \\
\text { Grushevsky } \\
\text { and A.A. } \\
\text { Ostapenko } \\
\text { (2012) }\end{array}$ \\
\hline
\end{tabular}

The technologies and methods described above for designing the content of academic disciplines are aimed at rethinking the presentation of educational information by teachers. In our opinion, it is of great importance to take into account the cognitive capabilities of each student [6].

From the point of view of the cognitive approach, cognitive processes, thinking are considered as dynamic structures - the processes of self-organization of complex systems. This approach allows us to reveal cognitive processes within the framework of the concept of emergence, which means the appearance of cognitive structures in the course of selforganization processes. In this regard, it is emphasized that for the manifestation of the creative activity of students, special stages or steps are required, associated with subconscious cognitive processes, which give thinking flexibility, freedom and unpredictability in the emergence of new ideas and creative solutions.

Thinking is presented as a dynamic structure - a process of self-organization, capable of constant change and cooperative interaction of various processes leading to a holistic education. The brain has a pronounced integrative ability. The huge flow of information in the modern world, which the student is unable to process, leads to the need to awaken creative activity and independence.

Thinking is based on the unity of the emotional and the rational, the interconnection of the perception of the procedural, temporary deployment of educational material with the patterns 
in the presentation of a simultaneous image with its possibilities of simultaneous holistic coverage of the phenomenon. The development of these ideas is associated with the problem of revealing the complex interaction of the right and left hemispheres, with the dominance, as a rule, in each specific case of one of them. The process of cognition (cognitivity), being a feature of human thinking, occurs using two mechanisms: the first is interconnected with rational-logical thinking, the second determines the importance of working with image models and is associated with figurative thinking. Both types of thinking, carried out in different hemispheres of the brain, are independent channels for processing ideas about the external world (Figure 1).

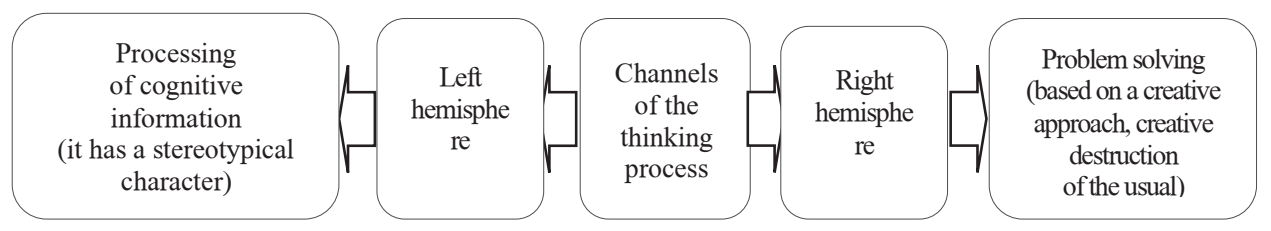

Fig. 1. Scheme of information processing in the process of thinking.

In turn, the interconnected work of the left and right hemispheres determines the characteristics of the thinking and behavior of the individual (Figure 2).

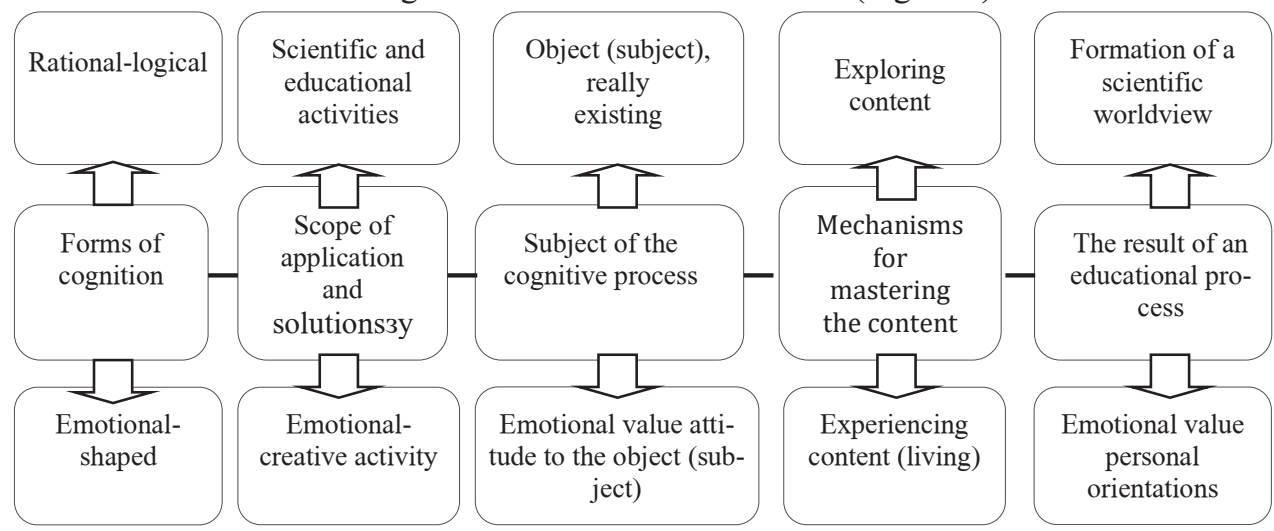

Fig. 2. Features of the integration of the cognitive and emotional components of cognition in the process of assimilating scientific knowledge.

In accordance with the cognitive theory, learning is not only the transmission of a certain amount of information, it is aimed at developing the ability to perceive educational material [7].

The quality of teaching is associated with the mental processes that arise in students. Perception play one of the important roles in the educational process, since it transforms information coming from the environment. The perception of real objects of reality proceeds on the basis of images, which further operate on cognitive processes [8].

"Perception (from Lat. perceptio) is a system for processing sensory data through unconscious and conscious filtration, sensual cognition of the surrounding world, subjectively presented as immediate" [9].

It is necessary in the process of organizing students' perception of educational material to carefully think over the order of presentation of the main points of the topic, to determine the connection between the new and the previously studied, etc., that is, to make the perception as easy and natural as possible. "Knowledge of the factors affecting perception, the basic principles of the organization of perceived images, the conditions for the occurrence of interference in the perception of educational material will help the teacher to better organize the learning process" [10]. 
The correct perception of the acquired knowledge contributes to its effective assimilation, determines the stable memorization of educational material, thereby affecting thinking. In this context, it is necessary to identify the personal meaning of scientific knowledge, which is facilitated by the expression of complex conceptual formations by figurative and metaphorical means (V.M. Polonsky, A.F. Zakirova, D.B. Bogoyavlenskaya, M.V. Klarin). In solving this problem, the development of the students' imagination takes a special place.

E.A. Klimov defines imagination as the ability to create images that were previously difficult to perceive [11].

The basis of imagination is the transformation of personal perception, which contributes to the development of students' creative thinking.

Determining the essential features of imagination, it should be emphasized that it is based on the process of transforming the ideas of a person, the appearance of other images. L.S. Vygotsky wrote: "The creative activity of the imagination is directly dependent on the richness and diversity of the previous human experience, because experience is the material from which the constructions of fantasy are created. The richer a person's experience, the more material his imagination has at his disposal" [12].

R.S. Nemov emphasizes that imagination determines the development of figurative thinking that solves educational tasks without the inclusion of practice-oriented actions, which, for one reason or another, cannot be carried out in a particular situation [13].

F.T. Mikhailov emphasizes that "productive imagination" is required and starting point for other forces of the soul. Namely, the power that realizes itself in dreams, and in intuition, and in intellect, and in higher emotions, and in a moral imperative ... and in will" [14].

It is the imagination that contributes to the solution of a problem that cannot be solved only by mental means. It contributes to the personal individualization of scientific knowledge not reproductively, but constructively, creatively."

According to E.V. Ilyenkov, a special place in comprehending the creative function of imagination is occupied by art as "a universal human ability, which, being developed, is realized in any sphere of human activity and cognition - in science, and in politics, and in everyday life, and in direct labor" [15]. Art allows to define the image of the "whole" before it is reproduced in a logical abstract system.

T.V. Sebar emphasizes the role of artistic imagination in synthesizing time, integrating past, present and future in the context of cultural values. "It is the artistic imagination that connects the heterogeneous and scattered in time and space of human perception into a single layer of individual human and social experience - culture" [16].

Figurative metaphor is often more accurate and personally convex than terminological unambiguity. Metaphors help to reflect the internal personally significant nature of the phenomenon under study, they are more informative in a semantic sense, since they are built on the basis of images. Imagination becomes a means of personal penetration of students on the basis of devination (getting used to) the content of scientific knowledge in the unity of the logical and emotional-figurative metaphorical development of the value nature of meaning, which contributes to the development of intuitive thinking. The search for new opportunities to improve the forms and methods of teaching allows to expand the understanding of existing private methods and enrich them with modern knowledge associated with various scientific areas.

Many psychologists emphasize the importance of overcoming the barriers of logical thinking in order to achieve creative freedom. One of the mechanisms is the development of fantasy, what is called the free play of the imagination. This mechanism largely contributes to the extrapolation of knowledge into new conditions, which makes it possible to integrate disparate layers of knowledge and skills and makes it possible to form a qualitatively new holistic education. 
The ability to present information from a new, extraordinary point of view, the ability to direct the attention of students to the problematic field of inexhaustible artistic knowledge provides a basis for creative development. The implementation of self-development, selfknowledge is associated with a continuous creative search for new solutions that open up space for imagination, imagination and make it possible to create an individual product, not to be afraid of bold, unexpected turns in solving professional problems.

Emotional-figurative self-realization is associated with a hermeneutic direction, according to which, teachers must prepare students for perception, adjust them to experience and empathy. The essential position of hermeneutics for the educational environment is the assertion of the dialogic nature of understanding. The main thing in "understanding" education is the ability and desire to open up to what cannot be said, and the ability to experience this openness.

An important link in "understanding education" by means of art is emotional-figurative identification, a phenomenon that functions at various stages of the educational process.

At the first stage - the emergence of a pedagogical concept - the teacher's emotionalfigurative identification appears in the most general form. The principles of exposure are discussed here.

At the second stage - the development of the concept - emotional-figurative identification is already more active, possible options are obtained in the system of pedagogical communication.

At the third stage - the embodiment and implementation of the plan - emotionalfigurative identification acts as a general principle of feedback in communication.

At the fourth stage of pedagogical creativity, emotional-figurative identification helps the teacher to present the results of the activity. Here emotional-figurative identification acts as an evaluative-clarifying element. The productivity of emotional-figurative identification is checked by the laws of logic and acts as an emotionally empathic student's self-realization, a kind of his figurative thinking.

Thus, the author reveals the importance of imagination, which ensures the effective harmonization of the cognitive and emotional aspects of the development of scientific knowledge.

\section{Materials and methods}

The task of the pedagogical process within the framework of cognitive didactics is aimed, first of all, at creating conditions for the development of an effective cognitive organization of human mental activity, equipping it with universal tools for solving educational, cognitive and life problems [17].

For this purpose, we used the diagnostics of the dominant perceptual modality by S. Efremtsev [18]. With the help of this diagnosis, it is possible to determine not only the leading type of information perception (auditory, visual or kinesthetic), but also the method of obtaining information and memory characteristics corresponding to each identified type. This diagnosis was supported by the study of the same students of imagination as a way of transforming personal perception, which contributes to the development of students' creative thinking [19].

The diagnostics we have chosen makes it possible to obtain brief qualitative characteristics of each type of perception of educational information by students in accordance with their inclination to intuitive thinking in accordance with that freedom of imagination, which allows extrapolating the acquired knowledge into new conditions, especially into the conditions of future professional activity. 


\section{Results and Discussion}

The survey involved 21 fourth-year students of the Department of Chemical Education of the Institute of Chemistry named after A.M. Butlerov of the Kazan (Volga Region) Federal University and 32 first-year students of two groups of the specialty "Law and organization of social security" of the first year of college at the private educational institution of higher education "Kazan Innovative University named after V.G. Timiryasov". The results of the survey on identifying the leading type of information perception by students are presented in Figure 3.

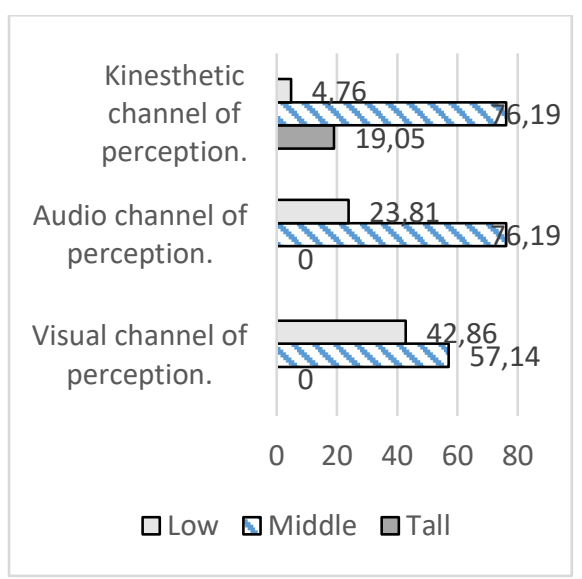

a) KFU

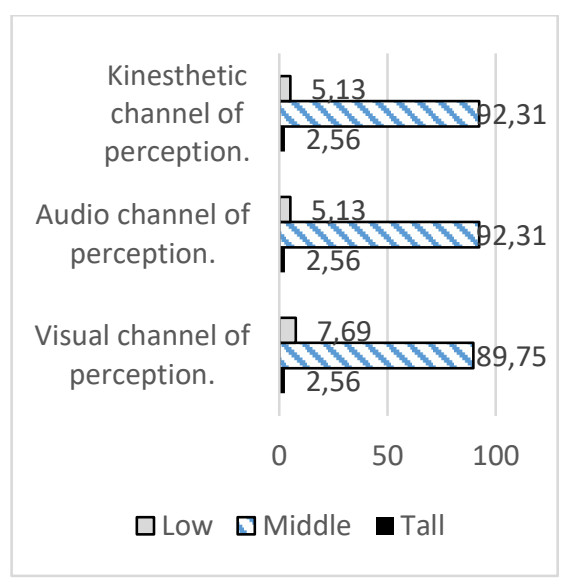

б) $\mathrm{KIU}$

Fig. 3. The results of the survey on the selection of the leading type of perception of information by students (\%).

The analysis of the results obtained indicates that for the majority of the surveyed students, all three types of perception of educational information (auditory, visual or kinesthetic) are developed at an average level in the range from $57 \%$ to $92 \%$. It should be noted that among future chemistry teachers - students of the Institute of Chemistry of the KFU, almost $20 \%$ of students have a high level and $76 \%$ have an average level of the kinesthetic type of information perception. This is primarily due to the fact that chemistry is an experimental subject, i.e. the method of obtaining and sometimes confirming the truth of information is associated with an active experiment. In addition, all pedagogical disciplines teach students - future teachers to react to the actions of others (schoolchildren), to their movements and gestures, and this characterizes the very style of information perception. But for students of humanities studying in the area "Law and organization of social security", the picture of the distribution of numbers is somewhat different. They have exactly the same numbers for two indicators: visual and kinesthetic types of perception of educational information (low $-5.13 \%$, medium $-92.31 \%$, high $-2.56 \%$ ). This is evidence that future legal professionals are equally important in the way they receive information in the course of a conversation, dispute or exchange of information. The comparative characteristics of students - natural scientists and students - humanities are interesting, in our opinion, from the point of view of determining their degree of imagination (Fig. 4). 


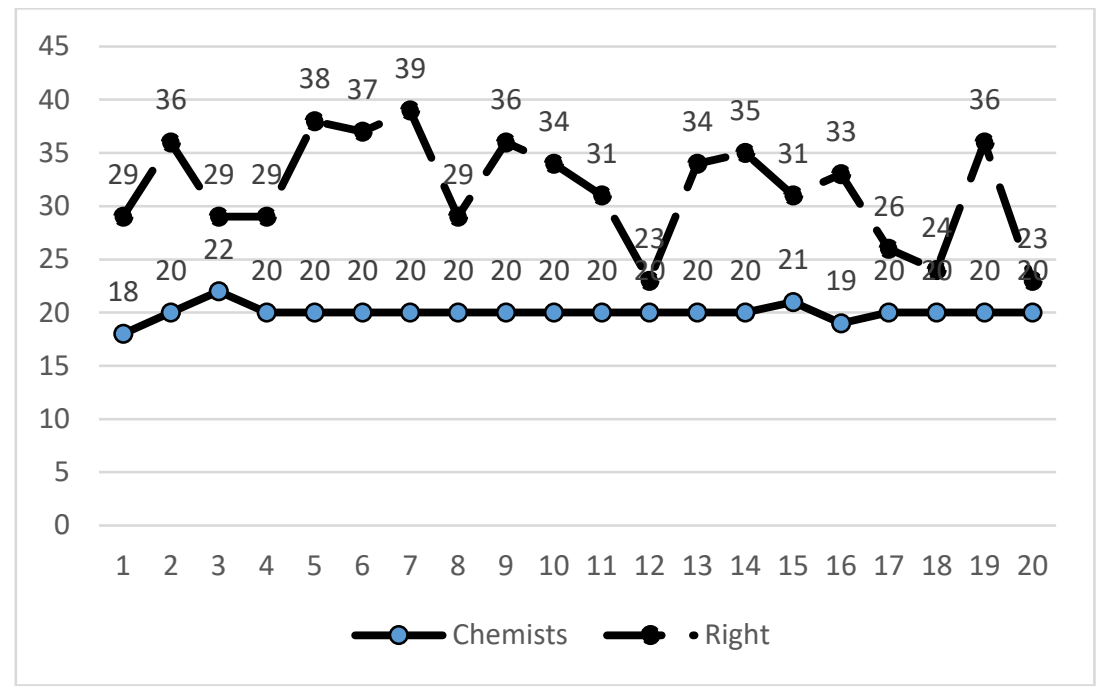

Fig. 4. The results of the survey to determine the degree of imagination of students.

According to the imagination test, students with more than 27 scores $(85 \%$ of those in the humanities) have a high level of imagination. While practically all students - chemists are at the average level of imagination, which is determined by the survey rules ranging from 13 to 26.

\section{Conclusion}

The conducted research orients us to the maximum use of the information received about the leading types of perception of information by students and the methods of obtaining information corresponding to each type in order to organize the thinking activity of students as efficiently as possible, to equip them with an internal universal toolkit for solving educational, cognitive and life problems in the conditions of modern requirements vocational education.

It is found that:

- correct perception of the acquired knowledge contributes to its effective assimilation, determines the stable memorization of educational material, thereby affecting thinking;

- the development of imagination contributes to the extrapolation of knowledge into new conditions, which allows integrating disparate layers of knowledge and skills, makes it possible to form a qualitatively new holistic education and overcome the barriers of logical thinking to achieve creative freedom.

So, we can state that:

- in the conditions of the current state of necessity of the generation of knowledge throughout the life, great importance belongs to cognitive didactics, in which special attention is paid to the study of the process of individual acquisition and transformation of educational information by students;

- the use of the mechanisms of art, artistic imagination on the basis of the integration integrity of the cognitive-logical and emotional-figurative components of cognition allows students to tune in to experience and empathy, which contribute to the assimilation of scientific knowledge not reproductively, but constructively, creatively;

- an important link in the cognitive organization of cognitive activity as a condition for the development of creative semantic activity of students is emotional-figurative 
identification, a phenomenon that functions at various stages of the educational process and provides an effective harmonization of the cognitive and emotional aspects of mastering scientific knowledge.

- the use of diagnostics of the dominant perceptual modality of S. Efremtsev for determining the leading type of information perception allows to describe both quantitative and qualitative characteristics of the personal characteristics identified in the process of interviewing students, their method of obtaining information and memory features in order to design the optimal organization of educational and cognitive activity in the university.

This study cannot claim to fully consider the complex and multifaceted problem of organizing educational and cognitive activity in the context of intensive knowledge generation. The problems of cognitive modeling of conceptual, conceptual, procedural, structural and content characteristics of the organization of the educational and cognitive process seem to be important for further scientific research.

\section{Acknowledgements}

The article was written according to state assignment No. 0N59-2019-0013 "The problem of modern methodology for studying the formation and development of a person in the era of digitalization"

\section{References}

1. R. Kh. Gil'meeva, et al., Cognitive pedagogy: an educational and methodological manual (2020)

2. V. S. Avanesov, Educational technology, 2 (2014)

3. Instrumental didactics and teaching design: theory, technology and practice of multifunctional imaging of knowledge: proceedings of the First all-Russian scientificpractical conference (2013)

4. R. V. Gurina, Materials of the First All-Russian scientific and practical conference "Instrumental didactics and didactic design: theory, technology and practice of multifunctional visualization of knowledge" (2013)

5. S. P. Grushevskii, A. A. Ostapenko, Condensation of educational information in professional education (2012)

6. A. R. Kamaleeva, Bulletin of the Chuvash State Pedagogical University named after I. Ya. Yakovlev, 2 (2020)

7. Yu. V. Serebryakova, Actual problems of pedagogy: materials of the II International Scientific Conference (2012)

8. R. M. Granovskaya, Elements of pedagogical psychology (1981)

9. N. L Grokhul'skaya, Informatization of education 2001: materials of the All-Russian Conf. (2001)

10. V. A. Lektorskii, New philosophical encyclopedia (2010)

11. E. Stouns, Psychological theory and practice of teaching (1984)

12. E. A. Klimov, Fundamentals of psychology: A textbook for universities (1997)

13. L. S. Vygotsky, Psychology of human development (2005)

14. R. S. Nemov, Psikhologiya (1999)

15. F. T. Mikhailov, Selected works (2001) 
16. E. V. Il'enkov,Questions of aesthetics, 4 (1964)

17. T. V. Sebar, Productive imagination in various worldview models (2002)

18. Cognitive pedagogy: technologies of e-learning in the professional development of a teacher: monograph (2016)

19. Diagnostics of the dominant perceptual modality by S. Efremtsev https://nsportal.ru/

20. Test for the ability to imagine http://www.psi.lib.ru/ 